\title{
Cervical intraspinal extradural primitive neuroectodermal tumour in an adult
}

\author{
Pinelopi V Gogou', Myrsini J Balafouta', Constantinos S Gennatas², \\ Agatha Kondi-Paphiti ${ }^{3}$, Xenophon N. Papacharalampous ${ }^{4}$, \\ Vasiliki Michalaki², John R Kouvaris ${ }^{1}$ \\ 'Department of Radiation Oncology, Aretaieio University Hospital, \\ Athens, 11528 Greece \\ 'Department of Medical Oncology, Aretaieio University Hospital, \\ Athens, 11528 Greece \\ ${ }^{3}$ Department of Pathology, Aretaieio University Hospital, \\ Athens, 11528 Greece \\ ${ }^{4}$ Department of Radiology, Aretaieio University Hospital, \\ Athens, 11528 Greece
}

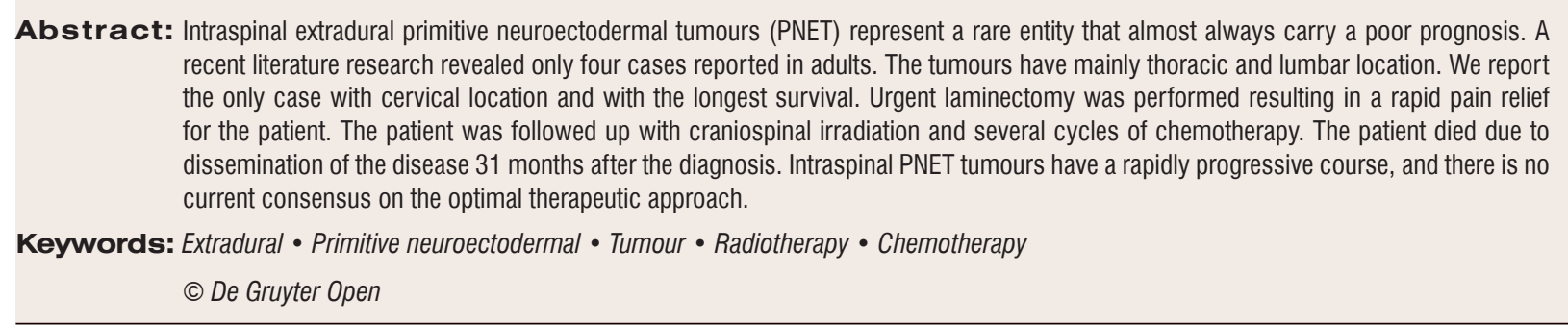

\section{Introduction}

Extracranial primitive neuroectodermal tumor (PNETs) originate from the soft tissues or bones outside the central or sympathetic nervous system and are composed of differentiated small, round, hyperchromatic tumour cells $(1,2)$. PNETs most commonly occur in the cerebellum (medulloblastomas), but can also arise from the pineal gland, cerebrum, spinal cord, brain stem and peripheral nerves $(3,4)$. Spinal PNETs are most common in adults (4-6), with a male predominance (4-6). Also, spinal PNETs have a tendency to metastasise outside neuroaxis with the most frequent sites being the lungs, bones and lymph nodes, similar to intracranial PNETs
(4-6). The aggressive nature of the tumour is highlighted by its rapid recurrence rate (4-7). Intraspinal PNET is an exceedingly rare entity $(8,9)$ with intradural location $(8,10)$ reported in all published cases. Extradural localisation of spinal PNET is more frequent in children; in adults, the commonest localisation is intradural or intramedullary (11-13). As far as the intraspinal extradural PNETs in adults are considered, after a review in the literature, only four cases have been described $(8,14-16)$, with a prevalence in thoracic and lumbar regions.

In this report, we describe the only case of extradural PNET with cervical location and the second oldest one. Our patient showed a long survival that might be due to the treatment she received. 


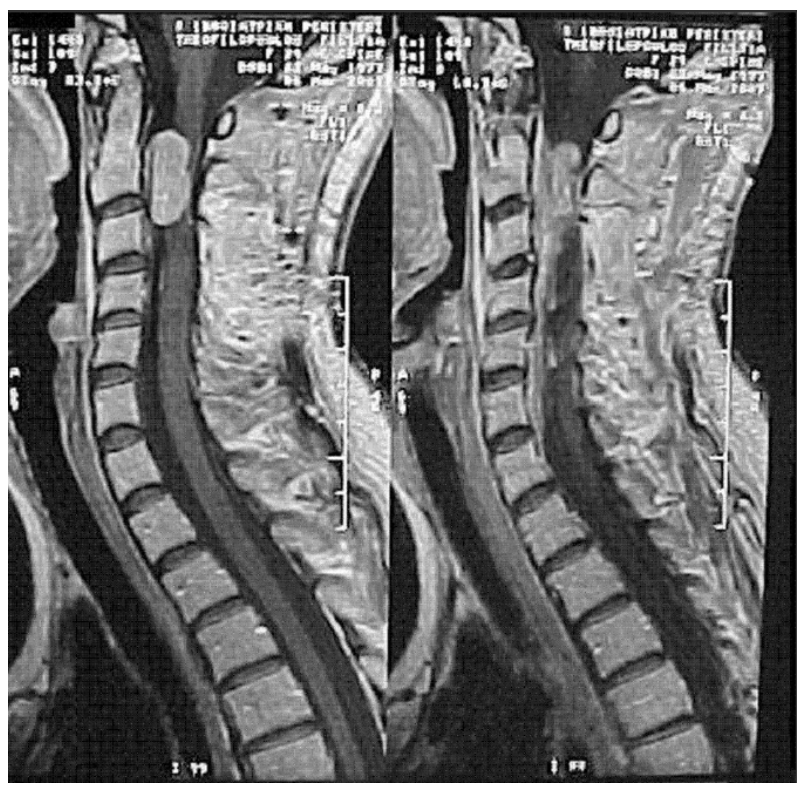

Figure 1. Magnetic resonance imaging with gadolinium enhancement at admission showing an intraspinal extradural mass extending from C1 to C6.

\section{Case report}

A formerly healthy 29-year-old female presented with a six-month history of neck pain followed by a rapidly progressive weakness and numbness in the upper extremities. Neurological examination revealed paraparesis of the upper extremities. Vital signs were within normal limit. There was no family history of any malignancy. Spinal magnetic resonance imaging (MRI) revealed a posterior extradural and paravertebral tumour extending from $\mathrm{C} 2$ to $\mathrm{C} 6$, causing compression of the spinal cord (Fig 1). Cranial MRI and thorasic and abdominal computerised tomography showed no added lesions. In February 2007, a laminectomy was performed at the C3-T4 level and the extradurally located mass was partial resected.

Histological and immune-histochemical examination of the tumour showed a round cell PNET with glial and cartilaginous differentiation (Fig 2). No other therapeutic intervention, such as radiotherapy (RT), was performed after the partial resection of the tumour. A month later, in March 2007, a new spinal MRI again showed an extradural tumour expanding from $\mathrm{C} 2$ to $\mathrm{C} 7$, with a larger diameter than previously and a slightly compressed spinal cord at the corresponding segments. In April 2007, a second urgent decompression excision of the tumour was performed as the patient was symptomatic with quadriparesis. A metastatic workup showed no evidence of an intracranial tumour or metastasis outside the neuroaxis. In May 2007, the patient underwent postoperative cerebrospinal irradiation. She received whole brain irradiation (50.4 Gy in 28 fractions) and $32.4 \mathrm{~Gy}$ in the spinal cord with a boost dose of $18 \mathrm{~Gy}$ given to the tumour itself. The total radiation dose targeting the tumour was 50.4 Gy given in 28 fractions. The tumour was dramatically reduced in size and, within the first week of RT, the patient regained the ability to walk and move her upper limbs. However, two months later, the tumour relapsed locally with a gradual spread to the neck region. Although no distant metastases were evident, the patient was reoperated, but the paresis of the left upper limb was not resolved. The patient received again a course of RT at the tumour bed after which she could move her upper left limb. Concomitantly, with the second RT course, the patient started chemotherapy with Ceeu $160 \mathrm{mg}$ and vincristine $1 \mathrm{mg} / \mathrm{m}^{2}$ every six weeks for a year. Six months after the completion of RT, the patient was generally doing well, with no clinical or radiological evidence of tumour recurrence. During the follow-up period, in June 2009, it was found on restaging that the patient developed metastatic disease. In spite of combinational chemotherapy and palliative RT for bone metastases, pain was present, and the patient died in September 2009, 31 months after the initial diagnosis.

\section{Discussion}

Peripheral primitive neuroectodermal tumours are aggressive, usually poorly differentiated, neoplasms of children and young adults, with a peak incidence seen at 


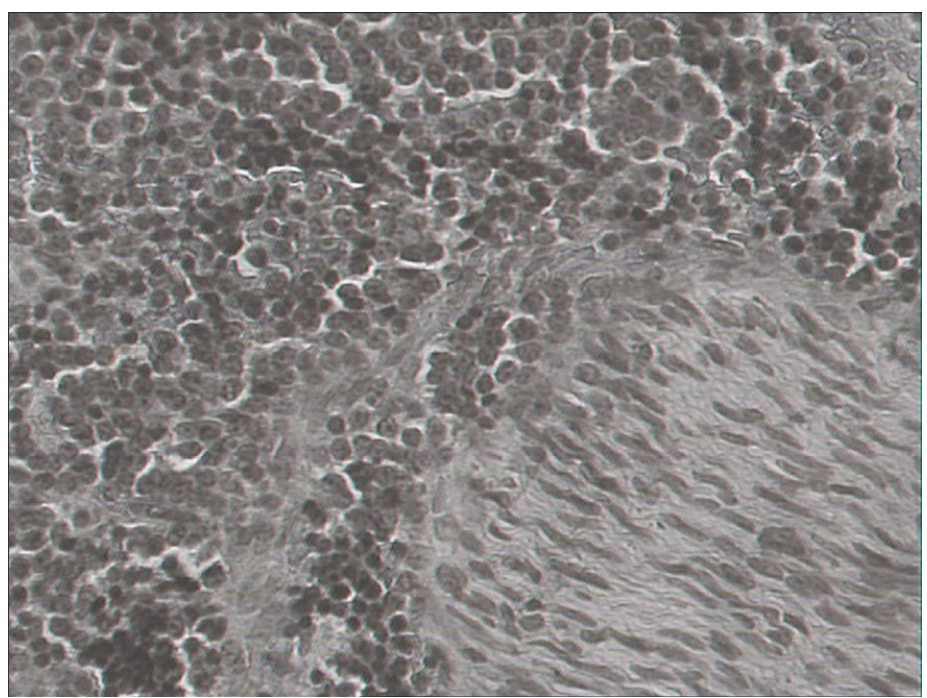

Figure 2. Light microscopic photograph showing a typical highly cellular pPNET tumour consisting of undifferentiated small round cells with frequent mitoses.

\begin{tabular}{|c|c|c|c|c|c|c|c|c|c|}
\hline AUTHOR & TIME & AGE & SEX & LEVEL & RESECTION & $\begin{array}{l}\text { ADDITIONAL } \\
\text { TREATMENT }\end{array}$ & RECURRENCE & METASTASIS & SURVIVAL \\
\hline Liu HM & 1987 & 26 year & $\mathrm{F}$ & L5/S1 & $\mathrm{CR}^{\star}$ & RT‡ & NO & & $\begin{array}{c}\text { alive at } 6 \\
\text { months }\end{array}$ \\
\hline Dorfmuller & 1999 & 32 year & M & S1 & $\mathrm{CR}^{*}$ & $\mathrm{RT} \neq+\mathrm{CHT \S}$ & LOCAL & & 29 months \\
\hline Musahl V & 2007 & 27 year & M & $\mathrm{S} 1-\mathrm{S} 2$ & $\mathrm{CR}^{\star}$ & $\mathrm{RT} \neq+\mathrm{CHT} \S$ & NO & $\begin{array}{l}\text { LUNG+ } \\
\text { MESENTERIC } \\
\text { NODULES }\end{array}$ & $\begin{array}{l}\text { alive at } 24 \\
\text { months }\end{array}$ \\
\hline Weber DC & 2004 & 26year & M & lumbar & $\mathrm{CR}^{*}$ & $\mathrm{RT} \neq+\mathrm{CHT}$ & LOCAL & & $\begin{array}{l}\text { alive at } 16 \\
\text { months }\end{array}$ \\
\hline Our patient & 2007 & 30 year & $\mathrm{F}$ & $\mathrm{C} 1-\mathrm{C} 4$ & PR† & $\mathrm{RT} \neq+\mathrm{CHT} \S$ & NO & $\begin{array}{l}\text { LUNG+ } \\
\text { BONE }\end{array}$ & $\begin{array}{c}\text { died at } 31 \\
\text { months }\end{array}$ \\
\hline \multicolumn{10}{|c|}{$\begin{array}{l}\text { * complete resection } \\
\text { † partial resection } \\
\text { † radiotherapy } \\
\S \text { chemotherapy }\end{array}$} \\
\hline
\end{tabular}

Table 1. Characteristics of patients.

the second decade of life $(9-11,15,16,18)$. PNETs of the spinal are a rare entity $(8,9,19)$; it has been postulated that they arise from neoplastic transformation of primitive neuroepithelial cells in subependymal zones $(8-10,15)$. A review of the literature shows that primary intraspinal PNETs can develop intramedullary or extramedullary, and intradurally or extradurally $(8-10,15)$. Primary spinal extradural PNETs in adults are extremely rare with only four cases reported in the literature so far (summarised in Table 1).
Symptoms of intraspinal PNETs are non-specific at the onset but as the disease progresses, neurological deficits mainly back pain, paresis of the limbs, sensory disturbances, and bladder and bowel dysfunction develop $(8-10,13-15,17,18)$.

The typical appearance of the PNET on CT scan resembles large non-calcified, soft tissue masses with cystic or necrotic areas and variable enhancement on post-contrast images $(8,9,15,20)$. Contrast-enhanced spinal MRI is particularly helpful in delineating the tumour 
extent and possible involvement of adjacent normal tissues by excluding further intraspinal metastases, as well as for the evaluation of resectability and response to therapy $(8-10,15)$. However, the final diagnosis of a PNET can only be made histologically $(8,9)$. Our patient was diagnosed indeed with a primary spinal extradural spinal PNET considering that the repeated brain and spine MRI scans did not reveal any evidence of primary cerebral tumour. Furthermore, the extradural location makes the possibility of being a drop metastasis unlikely.

The optimal therapy for PNET is still uncertain. There are no guidelines in the literature regarding the extent of the resection of the tumour and the intensity of the oncological treatment (chemotherapy or RT) (8). Initial treatment should be the gross removal of the tumour to clear if possible margins $(8,9,13,15)$. All four adult patients with PNET published in literature underwent total tumour resection $(8,14-16)$; however, two developed local recurrence $(15,16)$ despite total resection $(11,13)$. Other surgical approaches include laminectomy with partial tumour resection, often necessary for the relief of neurological symptoms and for obtaining bioptic tissue $(9,18,20)$. The later surgical procedure is associated with a greater incidence of distant metastasis, local recurrence and a higher mortality $(9,18)$. Our patient underwent laminectomy and partial tumour resection that resulted in complete relief of her symptoms that lasted for two months.

According to the literature, and based on the assumption that PNETs are chemosensitive and radiosensitive tumours, these modalities (chemotherapy and RT) present an important adjuvant treatment after the resection $(9,15)$. Literature on chemotherapy regimens is limited and current guidelines suggest the same treatment protocols as for medulloblastoma (8). The chemotherapy agents most commonly used include vincristine, adriaimycin, cyclophosphamide, ifosfamide and actinomycin-D, with their combination called VAIA $(8,9,13,16-18)$.

RT is an important treatment for PNET particularly in patients with incomplete resection of the primary tumour. Postoperative radiation therapy with doses up to $50 \mathrm{~Gy}$ of the entire neuroaxis (brain and spine) must be considered in order to achieve local control and reduce risk of metastasis $(8-10,15)$. The approach opted for our patient included partial resection of the tumour followed by RT and multiple sessions of chemotherapy. Most interesting in our patient was the delivery of craniospinal irradiation $(\mathrm{CSI})$ as she received the highest $\mathrm{RT}$ dose to counteract micromestasis in the spinal canal. The approach elected was compatible with the existing recommendations for treating medulloblastomas (8). It is possible that our patient has lived this long due to CSI treatment, despite the fact that the tumour was only partially removed. Three of the adult PNET published patients had received spinal axis segment irradiation $(8,14,15)$ and one was treated with CSI, though the RT dose was only 36 Gy (16). Three patients received concurrent chemotherapy and RT $(8,15,16)$ while one patient did not undergo chemotherapy as part of the primary therapy.

Prognosis of PNETs depends on several factors, such as tumour location and extension, resectability, and the presence of metastases (15). Average survival in most patients with intraspinal PNETs after combinations treatments is approximately 20 months $(8-10,15)$. Survival of adult patients with intraspinal extradural PNET ranged from 6 to 24 months $(8,14-16)$. Our patient succumbed to her aggressive disease 31 months after the initial diagnosis. This is the longest reported survival for adults with intraspinal PNET.

We believe that future advances in the treatment of PNETs lie in the field of chemotherapy and immunotherapy, especially for those patients presenting with disseminating disease. Nevertheless, early diagnosis, radical surgical excision and appropriate neuroaxis radiation offer better chances of a long survival and a good quality of life (10).

Note: Patient permission was obtained.

\section{Acknowledgements}

None declared

\section{Conflicts of interest}

None declared

\section{Funding}

No financial support 


\section{References}

[1] Ambros IM, Ambros PF, Strehl S, Kovar H,Gadner $\mathrm{H}$, Salzer-Kuntschik M. MCl2 is a specific marker for Ewings sarcoma and perifera primitive neuroectodermal tumours . Cancer 1991; 67: 18861893

[2] Dehner LP. Primitive neuroectodermal tumour and Ewing s sarcoma . Am J Surg Pathol 1993; 17:113

[3] Deme S, Ang LC, Skaf G, Rowed DW. Primary intramedullary primitive neuroectodermal tumour of the spinal cord: case report and review of the literature . Neurosurgery 1997; 41: 1417-1420

[4] Kosnik EJ, Bosel C, Bay J , Sayers MP. Primitive neuroectederaml tumours of the central nervous system in the childeren. J Neurosurg 1978; 48:741746

[5] Smith DR, Hardman JM, Earle KM. Metastazing neuroectedermal tumours of the central nervous system. J Neurosurg 1969; 31:50-58

[6] Sevick RJ, Johns RD, Curry BJ. Primary spinal neuroectodermal tumour with extraneural metastasis AJNR 1987;8:1151-1152

[7] Kaspers GJ, Kamphorst W, von de Graff M, van Alphen HA, Veerman AJ. Primary spinal epidural extraosseous Ewing sarcoma. Cancer.1991;68:648654

[8] Musahl V, Rihn JA, Fumich FE, Kang JD. Sacral intraspinal extradural primitive neuroectodermal tumour: a case report. The Spine J 2008;8:10241029

[9] Hariyama K, Oba Y, Mastuda S, Tanaka K, Chuman $\mathrm{H}$, Iwamoto $\mathrm{Y}$. Primitive neuroectodermal tumour and extraskeletal Ewing sarcoma arising primarly around the spinal column. Spine 2003;28:408-412

[10] Virani MJ, Jain S. Primary intraspinal primitive neuroectodermal tumor (PNET): a rare occurrences 2002;50:75-80

[11] Kumar R, Reddy S.J., Wani A.A., Pal L. Primary Spinal primitive neuroectodermal tumour: case series and review of the literature. 2006;43: 1-6
[12] Marwin C, Synowitz HJ, Kirches E, Kutz E, Dietzmann K, Weiss S. Primary primitive neuroectodermal tumor of the spinal cord: case report and review of the literature. Clin Neurol and Neuros.2002;104: 36-40

[13] Ozdemir N, Usta G, Minoglu M, Erbay AM, Berzigcioglu $H$, Tunakan $M$. Primary primitive neuroectodermal tumour of the lumbar extradural space. J Neurosurg Pediatrics 2008;2: 215-221

[14] Liu HM, Yang WC, Garcia RL, Noh JM, Malhotra $\mathrm{V}$, Leeds NE. Intraspinal primitive neuroectodermal tumour arising from the sacral spinal nerve. J Comput Tomogr 1987;11: 350-354

[15] Dorfmuller G, Wurtz FG, Umschaden HW, Kleinert $R$, Ambros PF. Intraspinal primitive neuroectodermal tumour; Report of two caese and review of the literature. Act Neurochir (Wien)1999;141:11691175

[16] Weber DC, Rutz HP, Lomax AJ, et al. First spinal axis segment irradiation with spot scanning proton beam delivered in the treatment of a lumbar primitive neuroectodetmal tumour. Case report and review of the literature. Clin Oncol. 2004;16:324-325

[17] Akai T, lizuka H, Kadoya S, Nojima T, Kohno M. Primitive neuroectodermal tumour in the spinal epidural space-case report., Neurol Med Chir, 1998;38:508-511

[18] He SS, Zhao J, Han KW, Hou TS, Nazakat H., Zhang S. Primitive neuroectodermal tumour of lumbar spine: case report. Chin Med J 2007;120(9):844846

[19] Balafouta M, Kouvaris J, Miliadou A, et al. Primitive neuroectodermal tumour in a 60-year-old man: a case report and review of the literature. The Brit $J$ Radiol 2002;75:62-65

[20] Boden SD, Wiesel SW. Lumbar spine imaging: role in clinical decision making. J Am Acd Orthop Surg 1996;4:238-24 